\title{
A Contrastive Study of Lexical Semantics in English
}

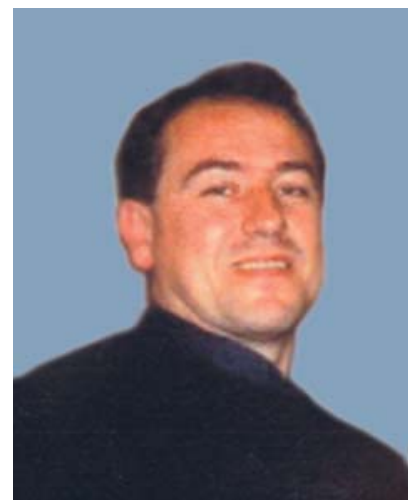

Carlos Inchaurralde
1. Lexical meaning. Types of meaning.

This paper presents current work about lexical semantics within a research project sponsored by the Spanish Ministry of Education, with the title "Contrastive Lexical Categorization, with Special Emphasis on English” (ref. BFF2002-168). This is a project about lexical denotative meaning, that is, referential meaning, so it is important to clarify from the beginning what we understand by denotation. Denotation is something that does not come out of the blue; it is learned. The more exposure one has to different manifestations of the denotative meaning of a word (together with the actual use of that word), the more clearly established the semantic content of that word will be in the end. We could call this acquisition mode 'cognitive extension', suggesting that our knowledge of the world is created through sensory interaction with our environment. Knowledge structures and the individual concepts that are associated with them are dynamically constructed. A systematic theory of how cognition is grounded in perceptual mechanisms, and how concepts are dynamically created in this way can be seen in the work of Barsalou and a team of co-workers (e.g. Barsalou 1982, Barsalou \& Sewell 1984, Barsalou 1993, Barsalou et al. 1993, Barsalou \& Prinz 1997).

On the other hand, when we learn new concepts at school, we often only receive concise explanations of the meaning of words. We may well call this type of meaning acquisition 'cognitive intension'. For decades, there was a perception that, if we wanted to study meaning, or even talk about it, it had to be made manageable (presumably because it was not thought to be). As a result, meaning was usually shrunk to presumably manageable proportions. Approaches to meaning were traditionally 'intensional,' i.e. based on the dictionary entry model. Denotational meaning was usually discussed in terms of (discrete) features or similar categories, articulated in different ways. However, after all the criticism that came from psycholinguistic empirical evidence (cf. Rosch 1973a, 1973b, 1975), it became clear that meaning does not consist of discrete features which are sufficient and necessary (cf. Geeraerts 1987). Rather, denotational meaning has an internal structure that relies on the distinction between prototypical and peripheral categories as well as between different levels of schematicity and specificity.

In addition, we must acknowledge that in the centre of any lexical meaning configuration there is always one (or, in some cases several) sense(s) to which all the 
others relate. In cognitive linguistics, the concept of a 'core meaning' from which different meaning extensions originate has clarified the issue. The theme of this approach is that conceptual categories have a radial structure (Lakoff 1987: 436). All members of a category are networked around a single core member. Radial structures have not been universally accepted, though. Cruse (1986) has pointed out that certain meaning structures do pose problems when conceived of as networks. When there is a connection between meanings along a continuum, normally developed in the course of time by means of metaphorical or metonymical processes, the idea of a 'sense-spectrum' may be more accurate. Cruse's own example is that of the mouth of a river, where the relevant meaning of mouth is just one of several along a spectrum (mouth of a person, mouth of a fish, mouth of a sea-squirt, mouth of a bottle, mouth of a cave, mouth of a river).

However, the established view remains that different but related meanings do not need to be graded along a continuum. On the contrary, the most common arrangement is a radial network in which the different extensions surround the main meaning. This configuration is geometrically similar to the family resemblance relations observed in prototype theory (Rosch 1973a, 1973b, 1975). For each category, there is a central example, and several peripheral instances that share only some characteristics (not necessarily the same throughout). This is the standard view. The 'extended' version of prototype theory (on the difference, cf. Kleiber 1991) acknowledges the possibility of configurations similar to Cruse's sense-spectra.

There are also other types of meaning that merit consideration. Another aspect of meaning is what has been referred to as the "connotations" of lexical items. There is a subjective dimension that has to be considered as well, and which, more importantly, can influence 'objective' meaning. The pioneering work in this area, and still one of the most salient references, is Osgood's research into what he calls 'semantic space'. Osgood (1976) presented a large number of subjects with a vocabulary sample, to which they had to assign different values on several bipolar scales consisting of qualifying adjectives. A factorial analysis of the data revealed three main dimensions (evaluation, potency and activity), which reflected the connotational configurations of the lexical items involved in the sample. In addition, other types of meaning have been identified from a psycholinguistic perspective. For instance, we have norms about features like 'familiarity,' 'concreteness' or 'imagery,' obtained through extensive sampling among speakers (Gilhooly \& Logie 1980, Paivio et al. 1968, Toglia \& Battig 1978; cf. Quinlan 1992).

Last, but not least, we must acknowledge the importance of encyclopaedic information, i.e. information about the world that goes beyond the simple label, the set of features or the referential link that can be provided in a mental 'dictionary' (cf. Inchaurralde 2000, Peeters 2000). This is real 'world knowledge'; it is part of the communicative context and it is there, inside our minds, in the form of semantic memory. Its role in language can be seen not only in inference processes, such as presuppositions, implicatures, etc., but also in the understanding of idiomatic expressions and creative metaphors. 


\section{Procedure. A practical case.}

Taking all these ideas into account, and hoping to discover new ways of classifying and presenting lexical meaning, we started specific work on different lexical units of the English language with the goal of analyzing their semantic structure. The first sub-goal was to identify a group of lexical items that could be of interest for such a piece of research. An important consideration here was that it should be a small set representative of basic English (that is, the most common kind of English) and, at the same time, useful from a pedagogical point of view, because we wanted to use the resulting list as a pedagogical tool. In order to obtain a list with such characteristics, we resorted to a lexical database from which we could create sub-lists. This lexical database was the Oxford Psycholinguistic Database (Quinlan 1992), which provides searches of vocabulary according to certain psycholinguistic parameters like the level of concreteness (how 'concrete' the referent is), familiarity (how 'familiar' the term is) and imagery (how easy it is to create and use 'images'). In this database it is also possible to select vocabulary according to its ranking in well-known frequency lists, like the LOB corpus (Hofland and Johansson 1982) and the Brown corpus (Brown 1984). This feature is also useful but it is slightly outdated nowadays, because it is now possible to resort to frequency lists based on corpora of millions of words (e.g. the COBUILD corpus or the British National Corpus).

With the help of the Oxford Psycholinguistic Database (Quinlan 1992) we arrived at a list of 1962 words which had high levels of concreteness, familiarity and imagery, as well as a high rank in the available frequency lists. We experimented with different weights in the different parameters and we called the procedure and results "a flexible model", with which we could get different lists according to different needs. In this case, due to the kind of work that we were going to carry out with the vocabulary, it was extremely important to have high levels of concreteness and imagery.

We took as a starting point the assumption that all lexical items have some sort of prototypical or core meaning, which could be identified in one of the senses provided by dictionaries. With this sense as the centre of the semantic structure, our task was then to set up radial networks with all the meanings.

In order to do this, we started with the definitions provided by the Merriam-Webster Dictionary (year 2001, electronic edition), but we are also comparing the results with entries in other dictionaries, especially when the configurations are not clear enough.

To keep things simple, we also assumed that the processes by means of which different meanings are connected are of four kinds:

- Generalization: From a more specific meaning to a more general meaning. (e.g. MONEY as 'something which can be exchanged for goods' is more general than 'coins and notes')

- Specification: From a more general meaning to a more specific meaning (e.g. BLOCK as 'the piece of wood on which the neck of a person condemned to be beheaded is laid for execution' is more specific than 'a compact solid piece of substantial material') 
- Metaphorical shift: The new meaning appears thanks to a metaphor. (e.g. BROTHER as 'a person related to another by common ties or interests' is a metaphor of 'a male who has the same parents as, or one parent in common with, another person'; metaphor is based on similarity of meaning)

- Metonymy: The new meaning appears thanks to a metonymy. (e.g. GUITAR as 'a certain musical instrument' leads to 'the person that plays the musical instrument', which is a metonymy; metonymy is based on contiguity of meanings)

As an example of this kind of work we have the following meanings for BED (taken from the current list in the project), whose semantic structure is reflected in Fig. 1:

(where $\mathrm{s}=$ specification, $\mathrm{g}=$ generalization, $\mathrm{m}=$ =metaphor, $\mathrm{n}=$ =metonymy)

1 bed $n$

$<$ A $>$

$<$ AAs $>$

$<$ AAAm $>$

$<$ ABs $>$

$<$ ABAn $>$

$<$ ACn $>$

$<$ ADn $>$

$<$ AEn $>$

$<$ AFm $>$

$<$ AFAs $>$

plot

$<$ AFBs $>$

$<$ AFCs $>$

$<$ AFDs $>$

$<$ AFDsAs $>$

$<$ AFDsAsAn $>$

$<$ AGm $>$ a piece of furniture on or in which to lie and sleep

a place of sex relations

marital relationship

a place for sleeping

sleep also: a time for sleeping <took a walk before $\sim>$ mattress filled with soft material

\section{bedstead}

the equipment and services needed to care for one hospitalized patient or hotel guest

a flat or level surface

a plot of ground prepared for plants; also: the plants grown in such a

the bottom of a body of water; $e$ sp: an area of sea bottom supporting a heavy growth of a particular organism <an oyster $\sim>$

a supporting surface or structure: foundation

\section{layer, stratum}

the place or material in which a block or brick is laid

the lower surface of a brick, slate, or tile

a mass or heap resembling a bed $<$ a $\sim$ of ashes $>$

$<$ served on a $\sim$ of lettuce $>$ 


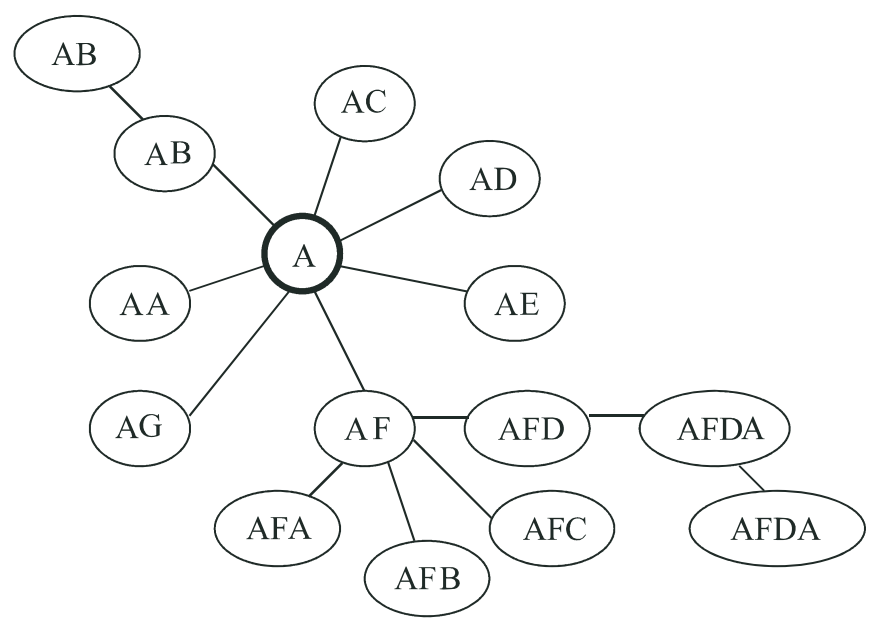

Fig. 1 The semantic structure of the lexical item BED

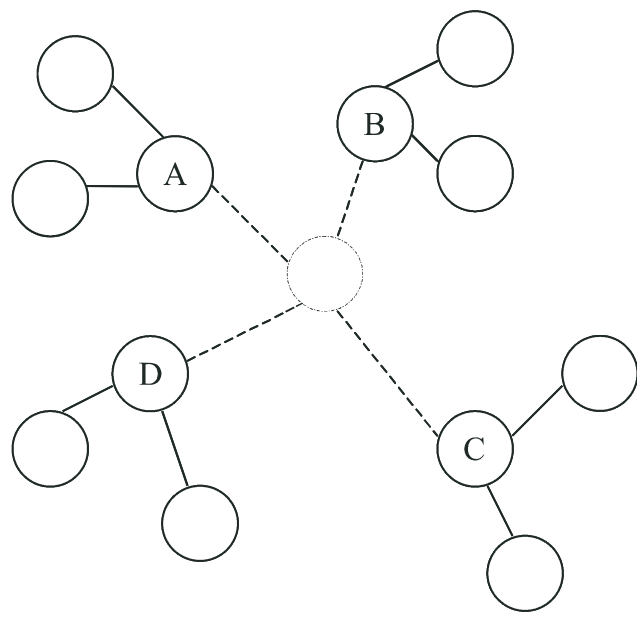

Fig. 2. A semantic structure without a centre

\section{Implementation problems. Conclusion.}

As this is an ongoing project, it is still early to have clear results, but we expect to find patterns which will allow us to make generalizations about the semantic structure of English vocabulary. Now we can already mention some interesting points, especially concerning certain difficulties that have appeared. Some of them (followed by concrete practical answers) are the following:

(1) It is not clear whether the core meaning has to be the most prototypical (most 
'typical' or characteristic meaning of a category) or the most schematic (more generic meaning).

They may coincide or not. When they do not coincide, it is useful to take the prototype. Sometimes the most schematic meaning does not appear and we may have several centres (see Fig. 2 as compared to Fig. 1).

(2) In some items it is difficult to see which one is more prototypical. We would need to turn to psycholinguistic evidence, which is not always available.

(3) In some cases, it is impossible to know what comes first: the most general or the most specific meaning. Our criterion is to trust intuition, which follows the mostreadily accepted meaning (psychological adequacy). But sometimes there are good underlying historical reasons.

(4) Some entries have several, apparently unrelated, very specific meanings. This poses a problem and, again, we have several centres, but without a unifying schematic meaning.

(5) In many cases, several processes take place at the same time. This is what happens, for instance, in metonymy-based metaphors. A practical example is the term CLOSET, for which we have $<\mathrm{A}>$ 'an apartment or small room for privacy', $<\mathrm{ACg}>$ ' $\mathrm{a}$ place of retreat or privacy', and $<\mathrm{ACn} / \mathrm{m}>$ 'a state or condition of secrecy, privacy or obscurity'. This last meaning can be considered to be a metonymy-based metaphor.

It is still early to see whether all these difficulties can help or hinder the drawing of some useful conclusions from this work. In any case, this research project seems interesting for new lexicographic work because it adds a new perspective to what has been done up to now and tries to incorporate ideas from the prototypical approach to categorization and psycholinguistic information. We hope in this way to fill a gap. Further work within this project will also be the comparison with configurations found in a basic Spanish vocabulary, but this is still to be done.

\section{References:}

1. Barsalou, Lawrence W. Context-Independent and Context-Dependent Information in Concepts. In: Memory and Cognition, 1982, 10, p.82-93.

2. Barsalou, Lawrence W. Flexibility, Structure and Linguistic Vagary in Concepts. Manifestations of a Compositional System of Perceptual Symbols. In: Collins, Alan F. Theories of Memory ed. by Gathercole, Susan E.; Conway, Martin A.; Morris, Peter E. Hillsdale, Lawrence Erlbaum, 1993, p.29-101.

3. Barsalou, Lawrence W., Prinz, Jesse J. Mundane Creativity in Perceptual Symbol Systems. In: Creative Thought. An Investigation of Conceptual Structures and Processes ed. by Ward, Thomas B.; Smith, Steven M.; Vaid, Jyotsna. Washington, D.C., American Psychological Association, 1997, p.267-307.

4. Barsalou, Lawrence W., Sewell, Daniel R. Constructing Representations of Categories from Different Points of View. In: Emory Cognition Project Technical Report 2. Atlanta, Emory University, 1984. 
5. Barsalou, Lawrence W.; Yeh, Wenchi; Luka, Barbara J.; Olseth, Karen L.; Mix, Kelly S.; Wu, Ling-Ling. Concepts and Meaning. In: Papers from the 29th Regional Meeting of the Chicago Linguistic Society, vol.2. Parasession on Conceptual Representations ed by Beals, Katharine; Cooke, Gina; Kathman, David; Kita, Sotaro; McCullough, Karl-Erik; Testen, David. Chicago, University of Chicago, 1993, p.23-61.

6. Brown, G.D.A. A Frequency Count of 190000 Words in the London-Lund Corpus of English Conversation. In: Behavioral Research Methods Instrumentation and Computers 1984, 16, p.503-32.

7. Peeters, Bert (Ed.) The Lexicon-Encyclopedia Interface. Amsterdam, Elsevier, 2000.

8. Cruse, D.Alan. Lexical Semantics. Cambridge, Cambridge University Press, 1986.

9. Geeraerts, Dirk. On Necessary and Sufficient Conditions. In: Journal of Semantics 1987, 5, p.275-291.

10. Gilhooly, Kenneth J.; Logie, Robert H. Age of Acquisition, Imagery, Concreteness, Familiarity and Ambiguity Measures for 1944 Words. In: Behavioral Research Methods and Instrumentation 1980, 12, p.395-427.

11. Hofland, K.; Johansson, S. Word Frequencies in British and American English. Bergen, NAVF, 1982.

12. Inchaurralde, Carlos. Lexicopedia. In: The Lexicon-Encyclopedia Interface ed. by Peeters, Bert. Amsterdam, Elsevier, 2000, p.97-114.

13. Kleiber, Georges. Prototype et prototypes. Encore une affaire de famille. In: Sémantique et cognition. Catégories, prototypes, typicalité ed.by Dubois, Danièle. Paris, CNRS, 1991.

14. Lakoff, George. Women, Fire and Dangerous Things. Chicago, University of Chicago Press, 1987.

15. Osgood, Charles. Focus on Meaning. In: Explorations in Semantic Space. The Hague, Mouton, 1976, v.I.

16. Paivio, Allan; Yuille, John C.; Madigan, Stephen A. Concreteness, Imagery and Meaningfulness Values for 925 Words. In: Journal of Experimental Psychology. Monograph Supplement, 1968, 76 (1:2).

17. Quinlan, Philip T. The Oxford Psycholinguistic Database. Oxford, Oxford University Press, 1992.

18. Rosch, Eleanor. Natural Categories. In: Cognitive Psychology. 1973a., 4, p.328-350.

19. Rosch, Eleanor. On the Internal Structure of Perceptual and Semantic Categories. In: Cognitive Development and the Acquisition of Language ed. by Moore, Timothy E. New York, Academic Press, 1973b, p.111-144.

20. Rosch, Eleanor. Cognitive Representations of Semantic Categories. In: Journal of Experimental Psychology: General. 1975, 104, p.192-233.

21. Rosch, Eleanor. Principles of Categorization. In: Cognition and Categorization ed.by Rosch, Eleanor; Lloyd, B.B. Hillsdale, NJ, Erlbaum, 1978. 
22. Toglia, M.P.; Battig, W.R. Handbook of Semantic Word Norms. New York, Lawrence Erlbaum, 1978.

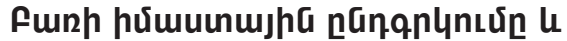

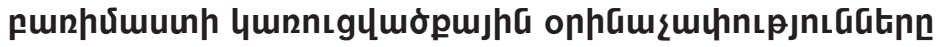 uliqutintianus}

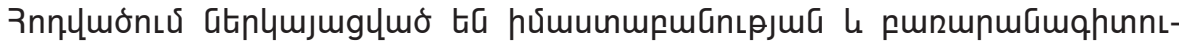

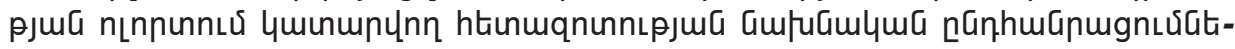

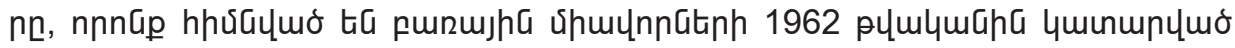

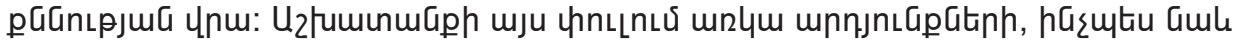

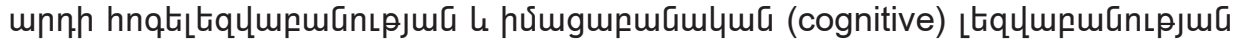

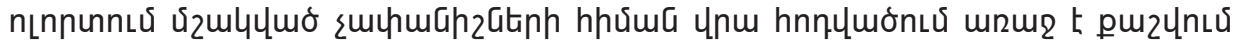

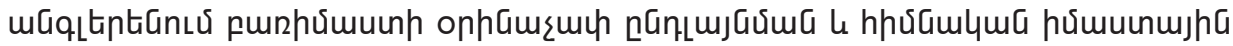

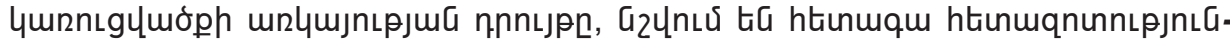

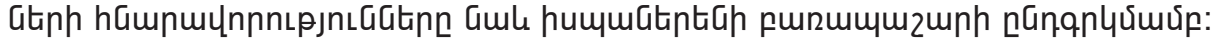

